\title{
Removal of Salt and Pepper Noise through Modified PSM Filter
}

\author{
Shivpratap Pandey \\ M.Tech \\ Department of Electronics and \\ Communication Engg. \\ Galgotias University \\ Greater Noida, India
}

\author{
Md. Rashid Ansari \\ Asst. Professor \\ Department of Electronics and \\ Communication Engg. \\ Galgotias University \\ Greater Noida, India
}

\author{
Rupali Kushwaha \\ M.Tech \\ Department of Electronics and \\ Communication Engg. \\ Galgotias University \\ Greater Noida, India
}

\begin{abstract}
In this paper, a new Modified Progressive Switching Median filtering algorithm is presented for the removal of salt and pepper noise from corrupted images. It sets a limit on the number of good pixel used in determine median and mean value and substitute to impulse pixel with the summation of its mean value and median value which is divide by 2.02 , after that pass through Gaussian filter. This scheme can remove salt and pepper noise with a noise level as high as 90\%. Experimental result shows that the proposed filter is superior over the traditional filter in maintaining higher PSNR (Peak Signal to Noise Ratio).
\end{abstract}

\section{Keywords}

Gaussian filter, Impulse Noise, IPSM, MATLAB, PSMF, PSNR

\section{INTRODUCTION}

Impulse Noise caused by malfunctioning pixel in camera sensors, faulty memory location in hardware or transmission in a noisy channel [1]. Impulse Noise also known as salt and pepper noise (respectively, random valued noise) and sparsely corrupts pixel to two intensity levels. The corrupted pixel is either set to a max value or zero value.

Applying of traditional median filter for removal of impulse noise gives relatively good response but analysis of different sources dedicated to median filtering shows, that the traditional manner filter has set of disadvantages.

- Signal weakening (object counters and edge are blurred in image).

- Affecting to non corrupted (good) image pixel.

Different modifications of median filter have been proposed to eliminate these disadvantages of median filtering. Now the Switching scheme attracts a high interest of many researches. This approach proves its efficiency for salt and pepper noise removal from digital image. The switching scheme approaches means splitting of noise removal procedure in to two main stages [2] [8].

a) Preliminarily detection of noise corrupted pixel of digital image in a progressively iterative manner. b) Filtering of noise Impulse which has been detected in first stage, also in a progressively iterative manner.

Modified PSM filter with the algorithm of Impulse detector remains the same as proposed by Wang and Zhou [3]. However, unlike PSM in noise filtering, the proposed work set the minimum number of noise free pixels that need to be used in finding the median and mean value [4] and substitute the noisy pixel with summation of median value and mean value which is divided by 2.02 and after that pass through Gaussian filter.

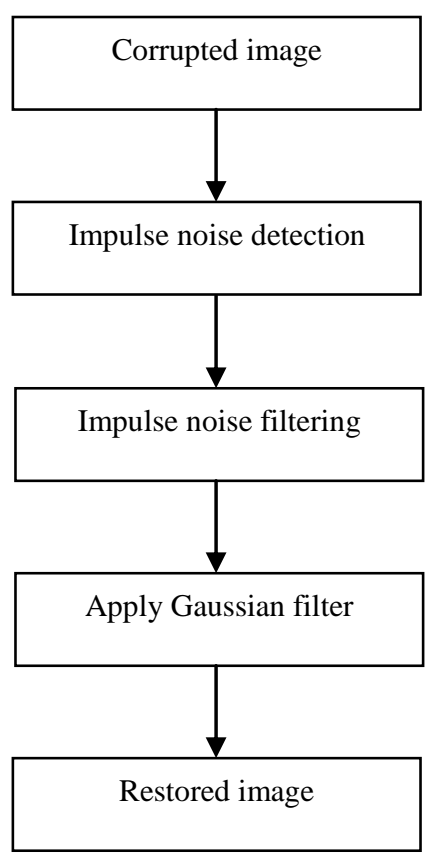

Figure 1: Flow chart of proposed method to reconstruct the Restored image

\section{MODIFIED PSM FILTER 2.1 IMPULSE NOISE DETECTION}

Using this detection algorithm, the median filter can avoid the replacement of noise-free pixel. 


\section{Steps:}

[1] Three parameters have to be determined in impulse detection, which are the window size of median filter $\left(\mathrm{W}_{\mathrm{D}}\right)$, number of iterations $\left(\mathrm{N}_{\mathrm{D}}\right)$, and threshold value $\left(\mathrm{T}_{\mathrm{D}}\right)$.

[2] For the best restoration: $N_{D}=3$ [3] [5].

[3] Initially $N_{I}=0$, Where $N_{I}$ is the number of noisy pixels that have been detected. For each pixel $\mathrm{x}_{(\mathrm{i}, \mathrm{j})}$, a median filter with $3 \times 3$ window is used to find its corresponding median value.

$$
\begin{aligned}
m_{(i, j)}= & \operatorname{Med}\left\{x_{(i, j)} \mid i-1 \leq i \leq i+1, j-1 \leq j \leq\right. \\
& j+1\}
\end{aligned}
$$

[4] The absolute difference between $\mathrm{m}_{(\mathrm{i}, \mathrm{j})}$ and $\mathrm{x}_{(\mathrm{i}, \mathrm{j})}$ is used to Determine whether the corresponding $\mathrm{x}_{(\mathrm{i}, \mathrm{j})}$ is an impulse or not. If it is an impulse, $\mathrm{N}_{\mathrm{I}}$ is increased by 1 , as given by:

$$
N_{I}=N_{I}+1 \text { if }\left|m_{(i, j)}-x_{(i, j)}\right| \geq T_{I}
$$

Where the threshold [1] $\mathrm{T}_{\mathrm{I}}$ is predefined as 40 [3].

[5] An estimation of the noise ratio, $R_{E}$ is given by:

$$
R_{E}=N_{I} / N
$$

Where $\mathrm{N}$ is the number of pixels in the image. This ratio is determined after all the pixels in the image have been filtered once.

[6] After that, $W_{D}$ and $T_{D}$ are determined based on $R_{E}$,

$$
W_{D}=3 \text { if } R_{E} \leq T_{R}
$$

Or,

$$
\begin{gathered}
W_{D}=5 \text { if } R_{E}>T_{R} \\
T_{D}=a+b \cdot R_{E}
\end{gathered}
$$

In order to find $\mathrm{W}_{\mathrm{D}}$ and $\mathrm{T}_{\mathrm{D}}$, a rough estimation on noise ratio is determined by implementing Sun and Neuvo's switch I scheme [2]. According to Wang and Zhang's PSM [3], where $\mathrm{T}_{\mathrm{R}}$, $\mathrm{a}$ and $\mathrm{b}$ are defined as $25 \%, 65$ and -50 respectively.

During impulse detection, two image sequences are produced. One is sequence of gray scale image $\left\{\left\{\mathrm{x}_{(\mathrm{i}, \mathrm{j})}^{(0)}\right\}\right\}$, $\left\{\left\{\mathrm{x}_{(\mathrm{i}, \mathrm{j})}^{(1)}\right\}\right\}, \ldots\left\{\left\{\mathrm{x}_{(\mathrm{i}, \mathrm{j})}^{(\mathrm{n})}\right\}\right\}$. The other sequence is binary flag image sequence $\left\{\left\{\mathrm{f}_{(\mathrm{i}, \mathrm{j})}^{(0)}\right\}\right\},\left\{\left\{\mathrm{f}_{(\mathrm{i}, \mathrm{j})}^{(1)}\right\}\right\}, \ldots\left\{\left\{\mathrm{f}_{(\mathrm{i}, \mathrm{j})}^{(\mathrm{n})}\right\}\right\}$.

Where,

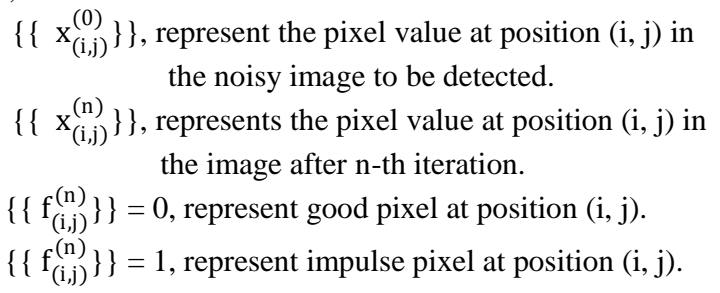

In the $\mathrm{n}$-th iteration $(\mathrm{n}=1,2, \ldots)$, the median value $\mathrm{m} \underset{(\mathrm{i}, \mathrm{j})}{(\mathrm{n}-1))}$ for each pixel $\mathrm{x} \underset{(\mathrm{i}, \mathrm{j})}{(\mathrm{n}-1)}$ is determined with a median filter with $\mathrm{W}_{\mathrm{D}} \times \mathrm{W}_{\mathrm{D}}$ window size

$$
m \underset{(i, j)}{(n-1)}=\operatorname{Med}\{x \underset{(i, j)}{(n-1)}\}
$$

Where,

$$
\begin{aligned}
& i=i-\left(W_{D}-1\right) / 2 \leq i \leq i+\left(W_{D}-1\right) / 2 \\
& j=j-\left(W_{D}-1\right) / 2 \leq j \leq j+\left(W_{D}-1\right) / 2
\end{aligned}
$$

when the absolute difference of $\mathrm{x}_{(\mathrm{i}, \mathrm{j})}^{(\mathrm{n}-1)}$ and $\mathrm{m} \underset{(\mathrm{i}, \mathrm{j})}{(\mathrm{n}-1)}$ exceeds the threshold $T_{D}$, the flag $\mathrm{f}_{(\mathrm{i}, \mathrm{j})}^{(\mathrm{n}-1)}$ is set to ' 1 '. Consequently, the processing pixel $x_{(i, j)}^{(n-1)}$ is substituted with the median pixel. Otherwise, both the flag and the processing pixel remain unchanged. This procedure is iterated for $\mathrm{N}_{\mathrm{D}}$ times.

$$
f_{(i, j)}^{(n)}=\left\{f_{(i, j)}^{(n-1)}\right\}, \text { if }\left|x_{(i, j)}-m_{(i, j)}\right|<T_{D}
$$

Else ,

$$
f_{(i, j)}^{(n)}=1
$$

And,

$$
x_{(i, j)}^{(n)}=m_{(i, j)}^{(n-1)} \text { if } f_{(i, j)}^{(n)} \neq f_{(i, j)}^{(n-1)}
$$

Or,

$$
x_{(i, j)}^{(n)}=x_{(i, j)}^{(n-1)} \text { if } f_{(i, j)}^{(n)}=f_{(i, j)}^{(n-1)}
$$

after $\mathrm{N}_{\mathrm{D}}$ iteration, then two output images $-\mathrm{x}_{(\mathrm{i}, \mathrm{j})}^{\left(\mathrm{N}_{\mathrm{D}}\right)}$ and $\mathrm{f}_{(\mathrm{i}, \mathrm{j})}^{\left(\mathrm{N}_{\mathrm{D}}\right)}$ are obtained, but only $\mathrm{f}_{(\mathrm{i}, \mathrm{j})}^{\left(\mathrm{N}_{\mathrm{D}}\right)}$ is useful for our noise filtering algorithm [6].

\subsection{Impulse noise filtering:}

The noise filtering procedure also produces two image sequences, one is a sequence of gray scale image, $\left\{\left\{\mathrm{y}_{(\mathrm{i}, \mathrm{j})}^{(0)}\right\}\right\}$, $\left\{\left\{\mathrm{y}_{(\mathrm{i}, \mathrm{j})}^{(1)}\right\}\right\}, \ldots\left\{\left\{\mathrm{y}_{(\mathrm{i}, \mathrm{j})}^{(\mathrm{n})}\right\}\right\}$. The other sequence is binary flag image sequence $\left\{\left\{\mathrm{g}_{(\mathrm{i}, \mathrm{j})}^{(0)}\right\}\right\},\left\{\left\{\mathrm{g}_{(\mathrm{i}, \mathrm{j})}^{(1)}\right\}\right\}, \ldots\left\{\left\{\mathrm{g}_{(\mathrm{i}, \mathrm{j})}^{(\mathrm{n})}\right\}\right\}$.

Where,

$$
\begin{aligned}
& \left\{\left\{\mathrm{y}_{(\mathrm{i}, \mathrm{j})}^{(0)}\right\}\right\}, \text { represent the pixel value at position }(\mathrm{i}, \mathrm{j}) \text { in } \\
& \text { the noisy image to be detected. } \\
& \left\{\left\{\mathrm{y}_{(\mathrm{i}, \mathrm{j})}^{(\mathrm{n})}\right\}\right\}, \text { represents the pixel value at position }(\mathrm{i}, \mathrm{j}) \\
& \text { in the image after } \mathrm{n} \text {-th iteration. } \\
& \left\{\left\{\mathrm{g}_{(\mathrm{i}, \mathrm{j})}^{(\mathrm{n})}\right\}\right\}=0, \text { represent good pixel at position }(\mathrm{i}, \mathrm{j}) . \\
& \left\{\left\{\mathrm{g}_{(\mathrm{i}, \mathrm{j})}^{(\mathrm{j})}\right\}\right\}=1, \text { represent impulse pixel which should be } \\
& \text { filtered. }
\end{aligned}
$$

Initially,

$$
g_{(i, j)}^{(0)}=f_{(i, j)}^{\left(N_{D}\right)}
$$

In the $\mathrm{n}$-th iteration $(\mathrm{n}=1,2, \ldots)$, the medium value $\mathrm{m}_{(\mathrm{i}, \mathrm{j})}^{(\mathrm{n}-1)}$ for each pixel $\mathrm{y}_{(\mathrm{i}, \mathrm{j})}^{(\mathrm{n}-1)}$ is determined with a median filter [9] with $\mathrm{W}_{\mathrm{F}} \times \mathrm{W}_{\mathrm{F}}$ window size. According to Wang and Zhang's PSM [3], $\mathrm{W}_{\mathrm{F}}=3$ is chosen for the best restoration. As in Wang and Zhang's PSM [3], the [10] median value $\mathrm{m}_{(\mathrm{i}, \mathrm{j})}^{(\mathrm{n}-1)}$ is determined from only good pixels with $\mathrm{g}_{(\mathrm{i}, \mathrm{j})}^{(\mathrm{n}-1)}=0$ in the $\mathrm{W}_{\mathrm{F}} \times \mathrm{W}_{\mathrm{F}}$ window. 


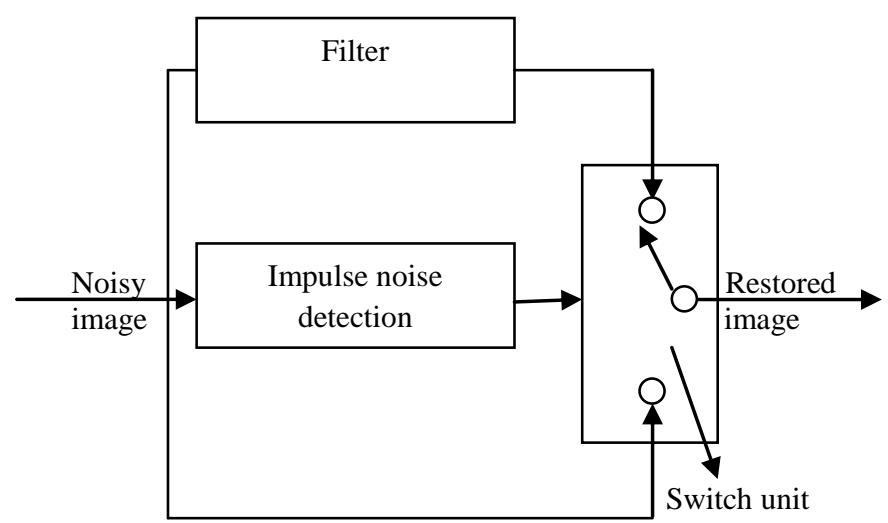

Figure 2: Switch scheme based framework

\section{Proposed method:}

Steps:

[1] In present work,,we set a limit to the number of good pixels that can be used to find the median value $\mathrm{m}_{(\mathrm{i}, \mathrm{j})}^{(\mathrm{n}-1)}$ and mean value $\bar{m}_{(\mathrm{i}, \mathrm{j})}^{(\mathrm{n}-1)}$.

$$
\begin{gathered}
m_{(i, j)}^{(n-1)}=\operatorname{Med}\left\{y_{(i, j)}^{(n-1)}\right\} \\
\bar{m}_{(i, j)}^{(n-1)}=\operatorname{Mean}\left\{y_{(i, j)}^{(n-1)}\right\}
\end{gathered}
$$

$$
\begin{aligned}
& i=i-\left(W_{F}-1\right) / 2 \leq i \leq i+\left(W_{F}-1\right) / 2 \\
& j=j-\left(W_{F}-1\right) / 2 \leq j \leq j+\left(W_{F}-1\right) / 2
\end{aligned}
$$

[2] Summation of equation (13) and equation (14) which is divided by 2.02 .After that, we substitute the impulse pixel with equation (15) as given below,

$$
s_{(i, j)}^{(n-1)}=\left(m_{(i, j)}^{(n-1)}+\bar{m}_{(i, j)}^{(n-1)}\right) / 2.02
$$

[3] $y_{(i, j)}^{(n)}$ is modified only when the pixel at $(i, j)$ is an impulse and $M$ is at least equal to $G_{P}$, where $M$ denotes the total Number of good pixels with $\mathrm{g}_{(\mathrm{i}, \mathrm{j})}^{(\mathrm{n}-1)}=0$ in the $\mathrm{W}_{\mathrm{F}} \times \mathrm{W}_{\mathrm{F}}$ Window, and $G_{P}$ denotes the number of good pixels that should be used in finding the corresponding median and Mean values, for best restoration $\mathrm{Gp}=5$ [5].

$y_{(i, j)}^{(n)}$ defined as:

$$
y_{(i, j)}^{(n)}=s_{(i, j)}^{(n-1)} \text { if } g_{(i, j)}^{(n-1)}=1 ; M \geq G_{P}
$$

Else,

$$
y_{(i, j)}^{(n)}=y_{(i, j)}^{(n-1)}
$$

[4] When either one of the criteria is not met, the noisy pixel is left unprocessed until further iterations to restore the noisy pixel. [11] The impulse pixel is considered as good pixel in the Subsequent iterations once it is modified as given by:

$$
g_{(i, j)}^{(n)}=g_{(i, j)}^{(n-1)} \text { if } y_{(i, j)}^{(n)}=y_{(i, j)}^{(n-1)}
$$

Or,

$$
g_{(i, j)}^{(n)}=0 \text { if } y_{(i, j)}^{(n)}=s_{(i, j)}^{(n-1)}
$$

[5] Noise filtering procedure terminates after the $\mathrm{N}_{\mathrm{F}}$ iteration With $\sum g_{(i, j)}^{\left(N_{F}\right)}=0$, Only then, we obtained the restored output image $\left\{y_{(\mathrm{i}, \mathrm{j})}^{\left(\mathrm{N}_{\mathrm{F}}\right)}\right\}$ and then pass through Gaussian filter [6].

\section{RESULT AND DISCUSSION}

Performances of algorithms are measured by calculating PNSR (Peak signal to Noise Ratio),

$$
P S N R=10 \log _{10}\{(255) 2 / M S E\}
$$

Where, Mean Square Error (MSE) is given by,

$$
M S E=1 / N \sum\left\{y_{(i, j)}^{\left(N_{F}\right)}-x_{(i, j)}^{(0)}\right\}^{2}
$$

Where $\mathrm{N}$ is the total number of pixels in the original image, $\mathrm{x}_{(\mathrm{i}, \mathrm{j})}^{(0)}$ is the pixel value at position $(\mathrm{i}, \mathrm{j})$ in the original image, And $y_{(i, j)}^{\left(N_{F}\right)}$ is the pixel value at position $(i, j)$ in the filtered image.

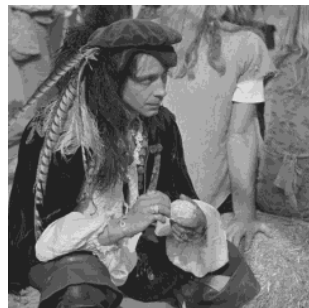

Figure 3: Original standard Pirate image for simulation results
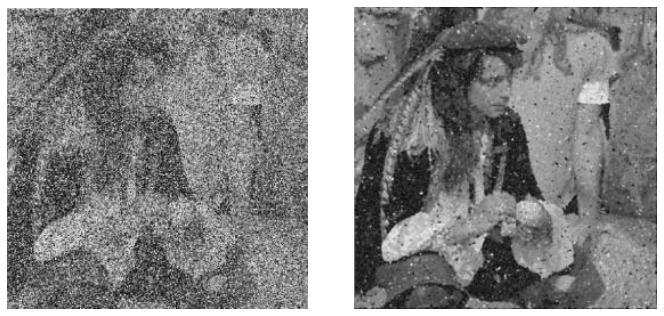

Figure 4: Result for Pirate image at $\mathbf{4 0 \%}$ noise level (a) corrupted image (b) restored image
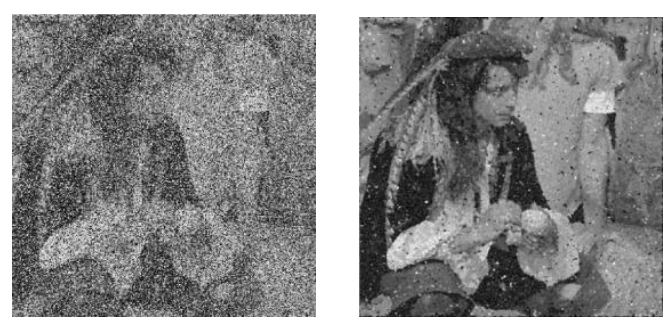

Figure 5: Result for Pirate image at 50\% noise level (a) corrupted image $(b)$ restored image 
Table 1: Comparison of PSNR (dB) values for different images using Proposed Algorithm

\begin{tabular}{|c|c|c|c|c|c|c|}
\hline \multirow{2}{*}{$\begin{array}{c}\text { Image } \\
\text { used }\end{array}$} & \multicolumn{6}{|c|}{ Noise percentage (\%) } \\
\cline { 2 - 7 } & 40 & 50 & 60 & 70 & 80 & 90 \\
\hline Rice & 23.92 & 20.58 & 15.22 & 12.80 & 11.21 & 9.10 \\
\hline Pirate & 24.52 & 21.36 & 15.27 & 12.72 & 10.70 & 9.02 \\
\hline Cameraman & 21.82 & 19.42 & 14.65 & 12.30 & 10.07 & 8.52 \\
\hline Moon & 24.80 & 20.71 & 16.81 & 12.98 & 8.55 & 6.80 \\
\hline Lena & 22.95 & 21.22 & 15.88 & 13.25 & 10.98 & 9.01 \\
\hline
\end{tabular}

Table 2: Estimated values of PSNR (dB) from different filters for 'LENA' $(256 \times 256)$ gray scale image

\begin{tabular}{|l|l|l|l|}
\hline \% NOISE & PSMF [3] & IPSMF [5] & PROPOSED \\
\hline 50 & 19.22 & 17.98 & 21.22 \\
\hline 60 & 12.12 & 12.98 & 15.88 \\
\hline 70 & 9.78 & 10.63 & 13.25 \\
\hline 80 & 7.98 & 8.90 & 10.98 \\
\hline 90 & 6.58 & 7.70 & 9.01 \\
\hline
\end{tabular}

Table 3: Comparison of estimated values of $\operatorname{PSNR}(\mathrm{dB})$ of different gray scale images $(256 \times 256)$ at a noise (Impulse Noise) level of $80 \%$

\begin{tabular}{|l|l|l|l|}
\hline IMAGE & PSMF [3] & IPSMF [5] & PROPOSED \\
\hline LENA & 7.98 & 8.90 & 10.98 \\
\hline CAMERAMAN & 7.59 & 8.86 & 10.07 \\
\hline RICE & 8.21 & 9.26 & 11.21 \\
\hline
\end{tabular}
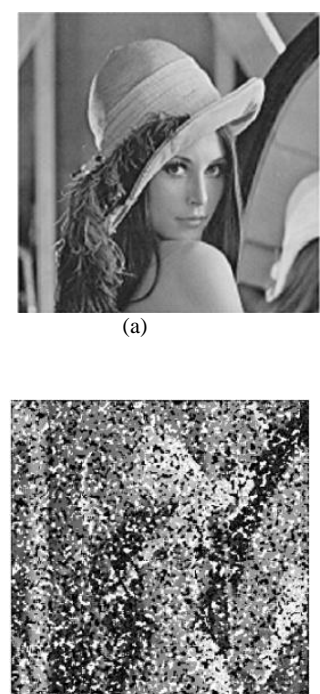

(c)
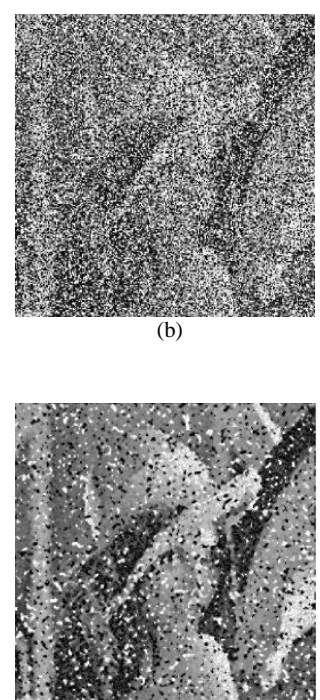

(d)

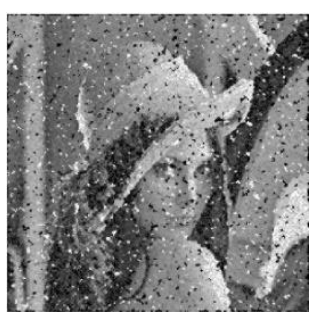

(e)

Figure 6: a) Original image, b) Corrupted image by $60 \%$ Impulse Noise, c) PSM filter [3], d) IPSM filter [5] e) Proposed filter

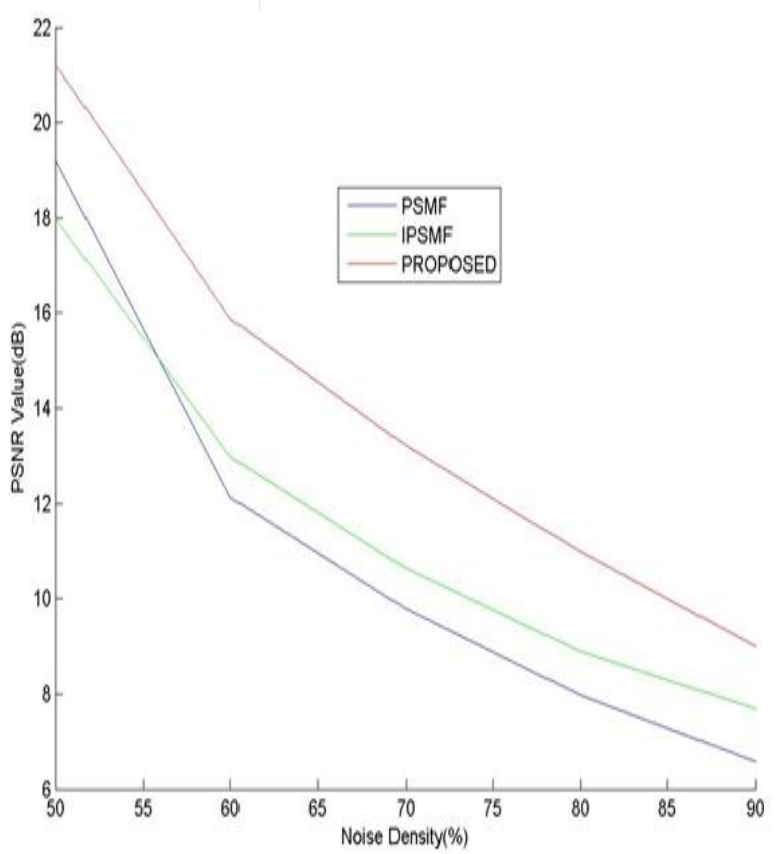

Figure 7: Plot PSNR Value of different filter over different noise density $(\%)$

In our experiment, we introduced fixed amount of impulse noise [6] [7] in to original image 'Lena'.

Fig(6) ,show that our proposed filter has better restoration particularly for highly corrupted images.

Table(1), shows that proposed algorithm provide better result for different images from noise level as high as $90 \%$.

\section{CONCLUSION}

The comparison of our proposed algorithm with the above mentioned techniques ( Table (1)) show that our algorithm outperforms several techniques even at high noise levels. Table(1) show that noise level $40 \%$ to $90 \%$ for a different image ,PSNR shows that proposed filter provide better restored image. The proposed filter provides better PSNR values(Table (2) and (3)) for Lena image compared to PSM[3] or IPSM[5] filter at noise level as high as $90 \%$.

The drawback with other methods introduced to handle high noise density fails as we increase the noise level. The main advantage of our algorithm is that its performance is not degraded with increasing noise level. It can easily handle high noise levels up to $90 \%$. 


\section{ACKNOWLEDGEMENT}

I express my thanks to Mr. R.S. Pandey and Mr. Deepak for sharing their valuable knowledge.

\section{REFRENCES}

[1] A. Bovik, Handbook of Image and Video Processing. New York: Academic, 2000.

[2] T. Sun and Y. Nuevo, "Detail preserving median based filters in image processing," Pattern Recognition. Lett, vol. 15, pp. 341-347, 1994.

[3] Zhou Wang and David Zhang, "Progressive switching median filter for the removal of impulse noise from highly corrupted images,"IEEE Trans. Circuits \& Systems II: Analog \& Digital Signal Processing, vol. 46, no. 1, pp. 78-80, Jan. 1999.

[4] J. Astola and P. Kuosmaneen, Fundamentals of Nonlinear Digital Filtering. Boca Raton, FL: CRC, 1997.

[5] Soon Ting Boo, Haidi Ibrahim, Member, IEEE and Kenny Kal Vin Toh, Student Member, IEEE, "An Improved Progressive Switching Median Filter", IEEE International Conference on Future Computer and Communication,2009
[6] R.C.Gonzalez and R.E. Wood, Digital Image Processing, Prentice-Hall, India, Second Edition 2007.

[7] A. K. Jain, Fundamentals of Digital Image Processing, Prentice Hall of India, 1989.

[8] Raymond H. Chan, Chung-Wa Ho, and Mila Nikolova, "Salt-and-Pepper Noise Removal by Median-Type Noise Detectors and Detail-Preserving Regularization," IEEE Trans. On Image Processing, vol. 14, no. 10, Oct. 2005

[9] K. K. V. Toh, H. Ibrahim, and M. N. Mahyuddin, "Saltand-pepper noise detection and reduction using fuzzy switching median filter," IEEE Trans. Consumer Electron., vol. 54, no. 4, pp. 1956-1961, Nov. 2008.

[10] S. K.Mitra and T.H. Yu. ,"Nonlinear Filters for Image Sharpening and Smoothing," In IEEE International Conference on Systems engineering, volume 4, pages $241-244$, August 1991

[11] S. Q. Zhang and M. A. Karim, "A new impulse detector for switching median filters," IEEE Signal Process. Lett, vol. 9, no. 11, pp. 360-363, Nov. 2002. 